\title{
Air Temperature Estimation by Using Artificial Neural Network Models in the Greater Athens Area, Greece
}

\author{
A. P. Kamoutsis, ${ }^{1}$ A. S. Matsoukis, ${ }^{1}$ and K. I. Chronopoulos ${ }^{2}$ \\ ${ }^{1}$ Laboratory of General and Agricultural Meteorology, Agricultural University of Athens, Iera Odos 75, 11855 Athens, Greece \\ ${ }^{2}$ Laboratory of Physics, Agricultural University of Athens, Iera Odos 75, 11855 Athens, Greece \\ Correspondence should be addressed to A.S. Matsoukis; armatsoukis@aua.gr
}

Received 8 July 2013; Accepted 12 September 2013

Academic Editors: F. Acs and T. Georgiadis

Copyright (c) 2013 A. P. Kamoutsis et al. This is an open access article distributed under the Creative Commons Attribution License, which permits unrestricted use, distribution, and reproduction in any medium, provided the original work is properly cited.

\begin{abstract}
Air temperature $(T)$ data were estimated in the regions of Nea Smirni, Penteli, and Peristeri, in the greater Athens area, Greece, using the $T$ data of a reference station in Penteli. Two artificial neural network approaches were developed. The first approach, MLP1, used the $T$ as input parameter and the second, MLP2, used additionally the time of the corresponding T. One site in Nea Smirni, three sites in Penteli, from which two are located in the Pentelikon mountain, and one site in Peristeri were selected based on different land use and altitude. $T$ data were monitored in each site for the period between December 1, 2009, and November 30 , 2010. In this work the two extreme seasons (winter and summer) are presented. The results showed that the MLP2 model was better (higher $R^{2}$ and lower MAE) than MLP1 for the $T$ estimation in both winter and summer, independently of the examined region. In general, MLP1 and MLP2 models provided more accurate $T$ estimations in regions located in greater distance (Nea Smirni and Peristeri) from the reference station in relation to the nearby Pentelikon mountain. The greater distance $T$ estimations, in most cases, were better in winter compared to summer.
\end{abstract}

\section{Introduction}

Urban climate, in general, is characterized by higher air temperature $(T)$ values compared to those at adjacent rural and mountainous regions. Increased urban $T$ contributes to increased emissions of power plants pollutants and of smog production, higher energy consumption, particularly for air-conditioning [1], and unpleasant thermal conditions to people, mainly during the warmest period of the year $[2,3]$, resulting, from a climatic point of view, in the degradation of human life quality. These conditions are associated in a high degree with urbanization of cities which is characterized as one of the most powerful anthropogenic forces all over the world [4]. Mountainous regions are distinguishable from urban regions due to their special pattern based mainly on the impact of topography and composition of vegetation $[5,6]$. It is well known that $T$ decreases as height increases in the troposphere [7], and a direct relationship has been reported between $T$ and the altitude of mountain regions [8]. These regions present improved bioclimatic conditions in relation to urban regions, especially in the summer, for example, the case of mountainous Nafpaktia [9], and they are used extensively as tourist destinations [10].

It has been reported that the microclimatic conditions in urban regions, for example, Athens, are influenced mainly by the ground cover type, which relates to the land use [11]. Since all ground cover types in urban regions are not covered by their meteorological stations (MSs), the estimation of microclimatic data is considered necessary for climatic and energy reasons. Also, in the case of mountainous regions, where the network of the meteorological stations at middle and high altitudes is sparse, there are many problems obtaining the precise meteorological data and their estimation at the aforementioned altitudes may be possible based on data collected from nearby lower-altitude areas [6].

Many researchers have examined the estimation of meteorological variables using various statistical techniques. Guler et al. [12] developed linear regression models to determine the mean distribution of $T$, relative humidity and rainfall data. Other researchers [13] combined regression and kriging techniques for $T$ interpolation. An artificial neural network (ANN) model is a robust computational technique [14] 
TABle 1: Measurement sites and dominated vegetation in the greater Athens area, Greece.

\begin{tabular}{|c|c|c|c|c|c|}
\hline Region & Locations & Site (altitude $(\mathrm{m})$ ) & Latitude & Longitude & Dominated vegetation \\
\hline Nea Smirni & Urban park & S1 [68] & $37^{\circ} 57^{\prime} 01.7^{\prime \prime} \mathrm{N}$ & $23^{\circ} 43^{\prime} 04.2^{\prime \prime} \mathrm{E}$ & $\begin{array}{c}\text { Pinus halepensis Mill., Eucalyptus sp., } \\
\text { Lantana sp., Lavandula angustifolia L., } \\
\text { grass species }\end{array}$ \\
\hline \multirow{3}{*}{ Penteli } & Pentelikon Mt. & S2 [1086] & $38^{\circ} 04^{\prime} 56.5^{\prime \prime} \mathrm{N}$ & $23^{\circ} 52^{\prime} 57.7^{\prime \prime} \mathrm{E}$ & Pinus halepensis \\
\hline & Pentelikon Mt. & S3 [796] & $38^{\circ} 03^{\prime} 44.1^{\prime \prime} \mathrm{N}$ & $23^{\circ} 50^{\prime} 51.9^{\prime \prime} \mathrm{E}$ & $\begin{array}{c}\text { Pinus halepensis, Thymus capitatus L., } \\
\text { Cistus sp. }\end{array}$ \\
\hline & $\begin{array}{c}\text { Former Merchant Navy } \\
\text { Hospital } \\
\end{array}$ & S4 [337] & $38^{\circ} 03^{\prime} 30.1^{\prime \prime} \mathrm{N}$ & $23^{\circ} 50^{\prime} 43.4^{\prime \prime} \mathrm{E}$ & $\begin{array}{c}\text { Pinus halepensis, Eucalyptus sp., } \\
\text { Pistacia lentiscus L. }\end{array}$ \\
\hline Peristeri & Agios Ierotheos & S5 [72] & $38^{\circ} 01^{\prime} 19.0^{\prime \prime} \mathrm{N}$ & $23^{\circ} 40^{\prime} 58.8^{\prime \prime} \mathrm{E}$ & - \\
\hline
\end{tabular}

Mt.: mountain.

which has been applied for the estimation of meteorological data as a function of the corresponding data of one or more reference stations. ANN models in many cases provide better estimations of $T$ in comparison with linear regression techniques, for example, [15]. Kisi and Shiri [16] reported that ANNs performed satisfactory estimations of $T$ and precipitation within a wide range of altitudes of Iran. The use of ANNs provided very satisfactory predictions of the discomfort levels during the hot season of the year in various regions of the GAA [17], as reported in the case of $T$ based on data in various agricultural regions in the United States of America [18]. Furthermore, ANNs gave very good estimations of biometeorological conditions in high altitudes in mountainous regions of Greece $[19,20]$.

The existed MSs in GAA do not cover all recent ground cover types and this study contributes a first step to address this insufficiency, in terms of $T$, a variable which is available in the majority of the MSs in Greece [6]. Thus, this study focuses on the estimation of $T$ data by using different ANNs approaches in urban and adjacent mountain regions of the GAA.

\section{Materials and Methods}

2.1. Study Regions and Measurement Sites. The field experiment was performed in three regions. The first one, the municipality of Nea Smirni (NS), lies on the southern part of GAA, about $5 \mathrm{Km}$ away from Athens, the capital of Greece. The region of NS possesses a central urban park which occupies an area of approximately 5 ha and contributes to a great degree to the recreation of visitors who come from many regions of Attica, Greece.

The second region, the municipality of Penteli, lies on the northeast part of GAA, about $12 \mathrm{Km}$ away from Athens. The city of Penteli is characterized by many open vegetated spaces and detached houses with gardens. A great part of this city lies on the foothills of the Pentelikon mountain, which was used in a great degree for marble mining in the past decades. Nowadays, the ecosystem of the Pentelikon mountain has been degraded in a large scale, due to the marble mining, the pressure of the building development, and the repeated events of fires which resulted mainly in many burned pine forest areas.
The third region, the municipality of Peristeri, is the metropolitan municipality on the western part of GAA, about $6 \mathrm{Km}$ away from Athens. The region of Peristeri is densely built with commercial and residential housing blocks and heavy traffic as in the case of NS.

One site in Nea Smirni, three sites in Penteli, and one site in Peristeri were selected based on different land use and altitude (Table 1 and Figures 1(a) and 1(b)). The altitude, the latitude, and the longitude of each site were evaluated using a mobile Global Positioning System (Garmin eTrex Vista) and cross-checked against 1:50000 topographic maps. The surrounding vegetation of the site S1 in Nea Smirni was irrigating in contrast with the natural vegetation of S2, S3, and S4 sites, in Penteli. There was no vegetation at S5 (Peristeri) but only asphalt and other structural materials.

2.2. Measurements and Neural Network Modeling. In each study site, $T$ data were monitored simultaneously every $10 \mathrm{~min}$ by sensors with data loggers (Hobo Pro v2, U23-001, Onset Computer Corporation, USA, accuracy $\pm 0.2^{\circ} \mathrm{C}$ for $T$ over $0^{\circ} \mathrm{C}$ to $50^{\circ} \mathrm{C}$ ) for the period between December 1,2009 and November 30, 2010. This period can be considered as representative for our study, because the mean $T$ values of the S4 site (reference site) during winter of 2009-2010 (9.9 $\left.{ }^{\circ} \mathrm{C}\right)$ and summer $2010\left(26.0^{\circ} \mathrm{C}\right)$ were similar to the respective values $\left(10.1^{\circ} \mathrm{C}\right.$ in winter and $26.0^{\circ} \mathrm{C}$ in summer) calculated from the MS of the National Observatory of Athens at Thissio for the base period from 1961 to 1990 [21], about $14 \mathrm{Km}$ away from S4 site. The instruments, before their installation in the measurement locations, were calibrated in the laboratory against reference sensors and tested for a period of five days. Additionally, every month, the instruments were tested in situ against reference sensors. These tests revealed no shift errors for any of the sensors. The instruments were enclosed in appropriate shelters screened from precipitation and direct solar radiation and mounded on selected plant species and pillars $1.5 \mathrm{~m}$ above ground surface. The aforementioned measuring height was selected for comparison reasons, taking into account that the meteorological shelter is located at the height of $1.5 \mathrm{~m}$ approximately above the ground surface [22]. Air temperature mean values were calculated on an hourly basis for every study site and separately for each month and 
season. In this paper, we present $T$ processing data for the extreme seasons of the year, winter and summer.

One of the most commonly used ANN architectures, the multilayer perceptron (MLP) with one hidden layer, was used for $T$ estimation in the present study. The site S4, was used as a reference station; that is to say, $T$ of $S 4$ was used to estimate $T$ for the other sites (S1, S2, S3, and S5). The maximum and minimum distances among $\mathrm{S} 4$ and the other measurement sites were 16.3 and $3.4 \mathrm{Km}$, respectively. For the training, the backpropagation algorithm was used [23-25]. A major consideration in the use of MLPs for model building is the determination of the optimal architecture of the network (number of inputs, number of layers, and number of nodes per layer). Usually, a trial and error method is applied to test various alternative models.

The MLPs developed and used in the present study are of two architectures (MLP1 1-6-1 and MLP2 2-6-1). The first (MLP1) had one input variable ( $T$ at the reference site); one hidden layer with 6 nodes, since it was found that this is the number of nodes that gave the best results; and one output (the temperature at the test sites). The only difference of the second architecture (MLP2) is that the input had two variables ( $T$ at the reference site and the time of the corresponding $T$ ). The activation function for the hidden layer was the hyperbolic tangent function, while for the output layer it was the logistic sigmoid function. The training set consisted of $1 / 2$ of the data, the selection set of $1 / 4$ of the data, and the test set of the remaining $1 / 4$ of the data, randomly assigned. All the results refer to the test set of the data. After applying the sensitivity test for the input variables, we found that all variables used (time of the corresponding $T$ and/or $T$ ) are significant to our model at $P<0.05$.

\section{Results and Discussion}

The results of the development and application of the MLP method at the examined sites of GAA are presented in Figures 2 and 3. In winter, $T$ estimations for the S1 site were very satisfactory in MLP1 and MLP2 models (Figure 2(a)) according to the higher values of the determination coefficient $\left(R^{2}>0.90\right)$ compared to the other examined cases (Figures 2(b), 2(c), and 2(d)). Furthermore, the efficiency of both MLP1 and MLP2 models to estimate $T$ in Nea Smirni based on $T$ of the reference site (S4) was strengthened by the lower MAE values in relation to the respective values of the other examined regions. The $T$ estimation in the case of S5 (Peristeri) may be considered as more accurate in comparison with S3 (Pentelikon Mt. alt. $796 \mathrm{~m}$ ) because MAE values were lower in S5 compared to S3 for both MLP1 and MLP2 (Figures 2(c) and 2(d)), although $R^{2}$ values were almost equal. These models provided less accurate estimations in the higher examined alt. of Pentelikon Mt. (1086 m) as both of them showed lower and higher values of $R^{2}$ and MAE, respectively, (Figure 2(b)) in comparison to the other studied regions. MLP1 and MLP2 models showed better $T$ estimations in regions located at greater distances from the reference site in relation to the nearby mountainous region.

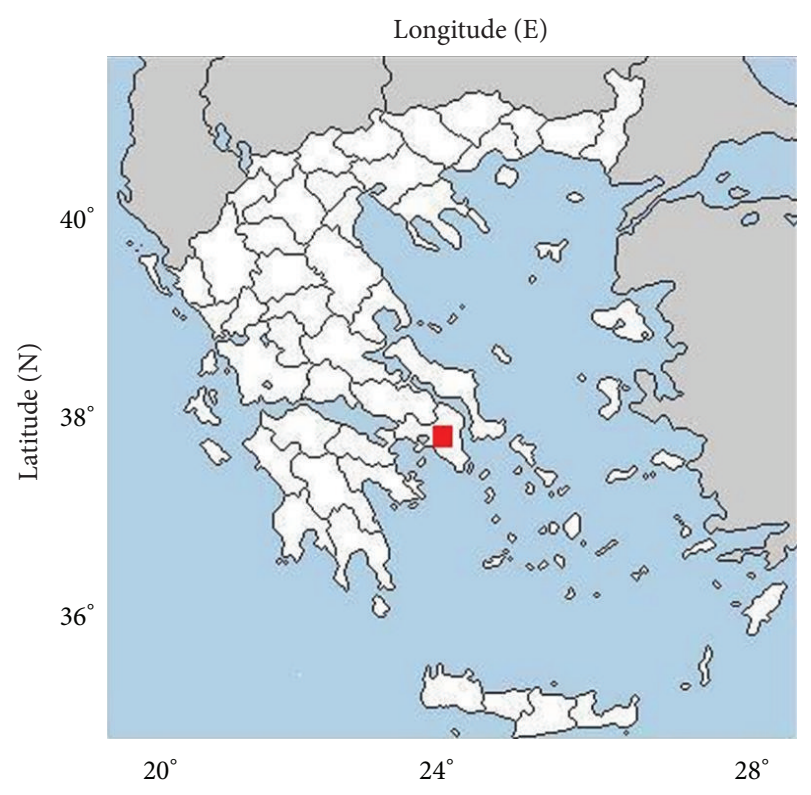

(a)

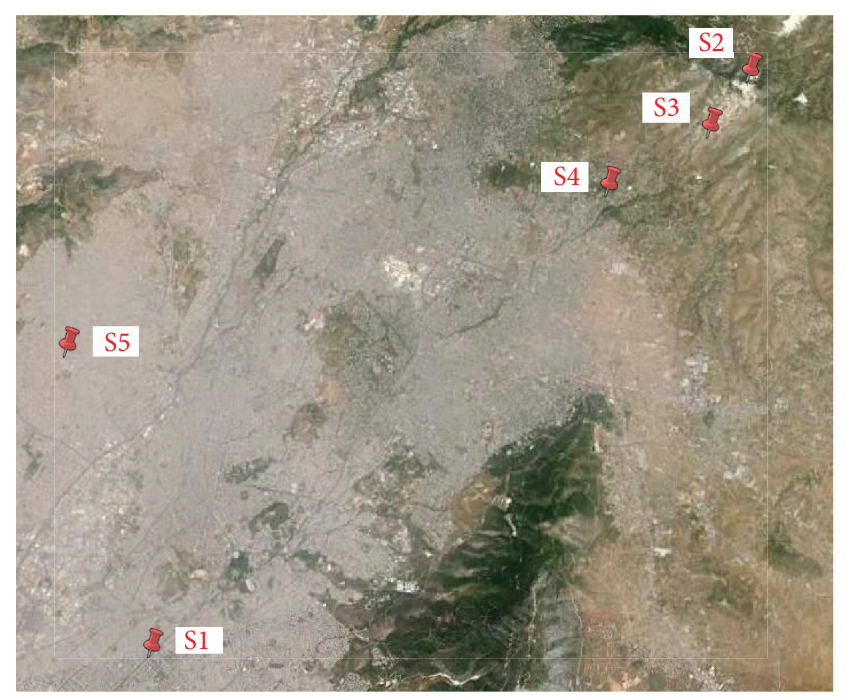

(b)

FIGURE 1: (a) Greater Athens area (square with red color) in Attica, Greece, and (b) measurement sites in the regions of Nea Smirni (S1), Penteli (S2, S3, and S4), and Peristeri (S5) (source: Google Earth 2013, on June 23, 2012).

In summer, the effectiveness in estimating $T$ at Nea Smirni site using MLP1 model (Figure 3(a)) was greater than the other respective cases of the rest examined sites (Figures 3(b), 3(c), and 3(d)) because of higher $R^{2}$ and lower MAE, as in the respective case of winter. By using MLP2 model, $T$ estimations were more accurate in both Nea Smirni (Figure 3(a)) and Peristeri (Figure 3(d)) because their examined sites presented equal values of $R^{2}$ and MAE which were higher and lower, respectively, in relation to the rest of the examined regions. The $T$ estimation in the case of the middle alt. (S3) of Pentelikon Mt. (Figure 3(c)) presented lower and higher $R^{2}$ and MAE values, respectively, 


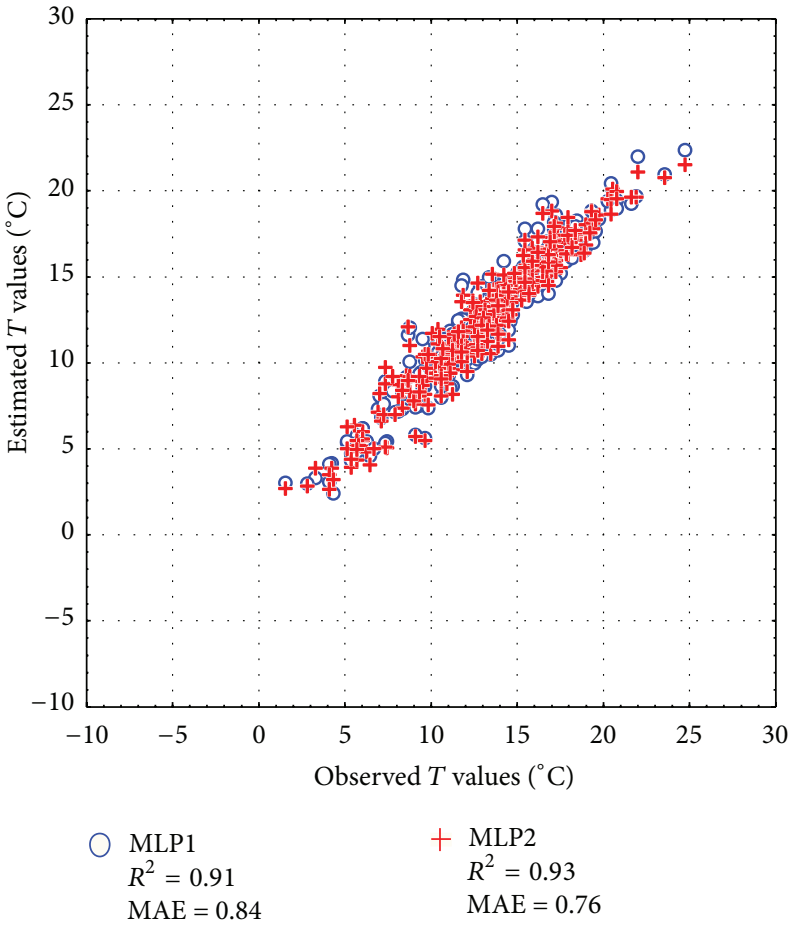

(a)

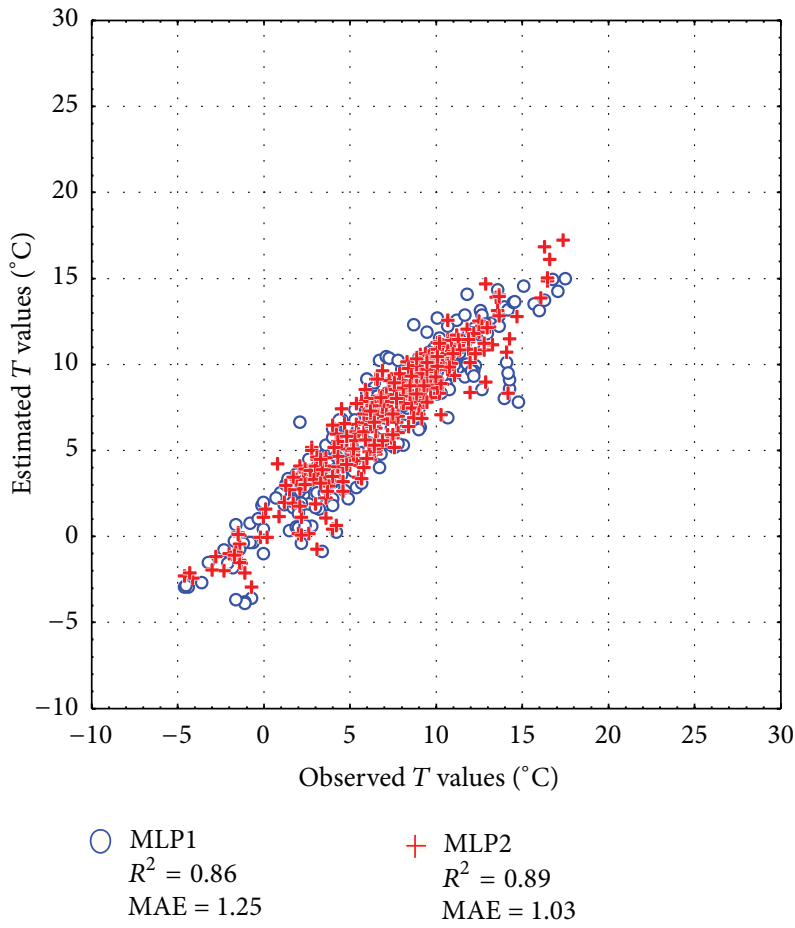

(c)

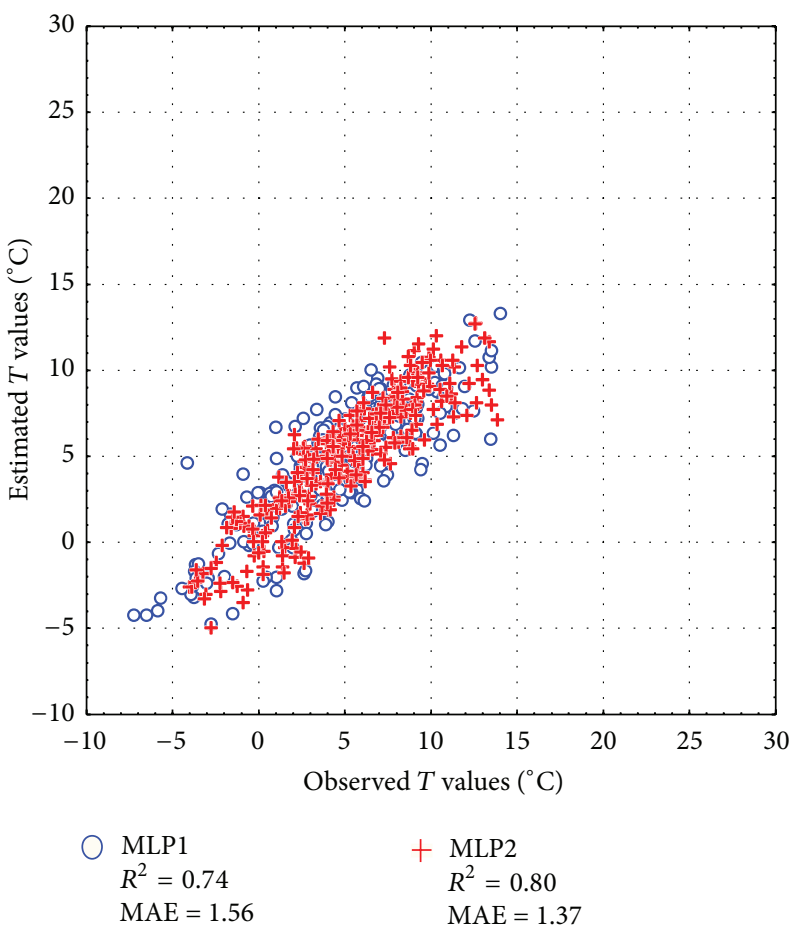

(b)

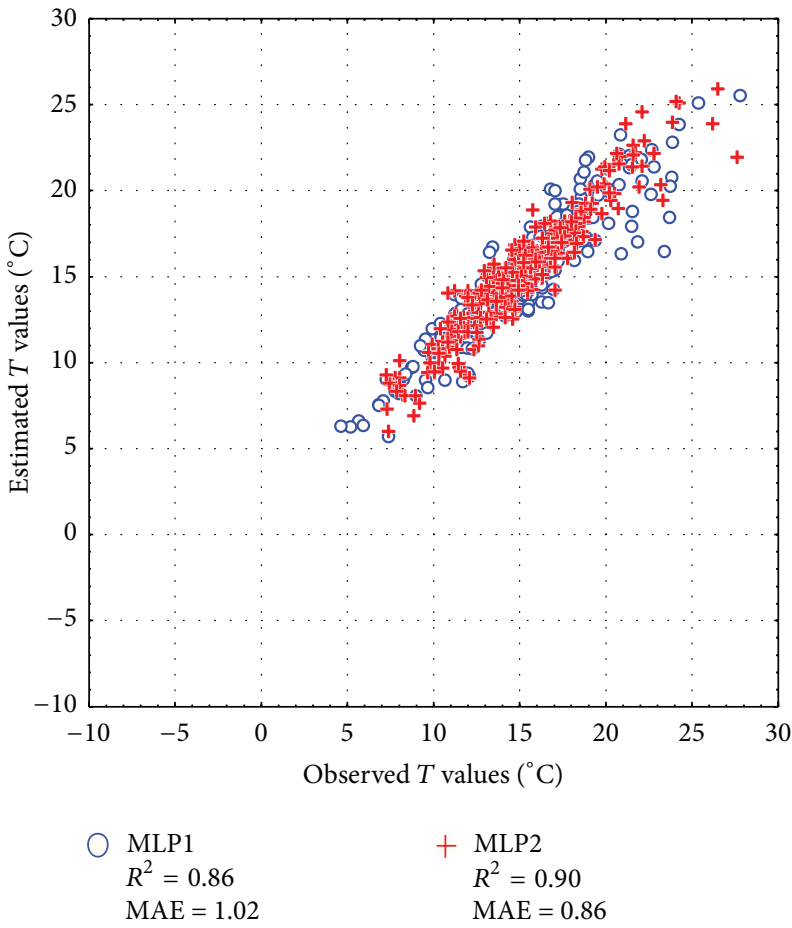

(d)

Figure 2: Scatterplots of observed versus estimated T values in (a) Nea Smirni (S1), (b) top (alt. $1086 \mathrm{~m}$ ) of Pentelikon Mt. (S2), (c) middle (alt. $796 \mathrm{~m}$ ) of Pentelikon Mt. (S3), and (d) Peristeri (S5) in the GAA, Greece, during winter of 2009-2010. T: air temperature, alt.: altitude, Mt.: mountain, GAA: greater Athens area, MLP1: multilayer perceptron model with $T$ as input parameter, MLP2: multilayer perceptron model with $T$ and time of the corresponding $T$ as input parameters, $R^{2}=$ coefficient of determination, $\mathrm{MAE}=$ mean absolute error, and $P<0.05$. 


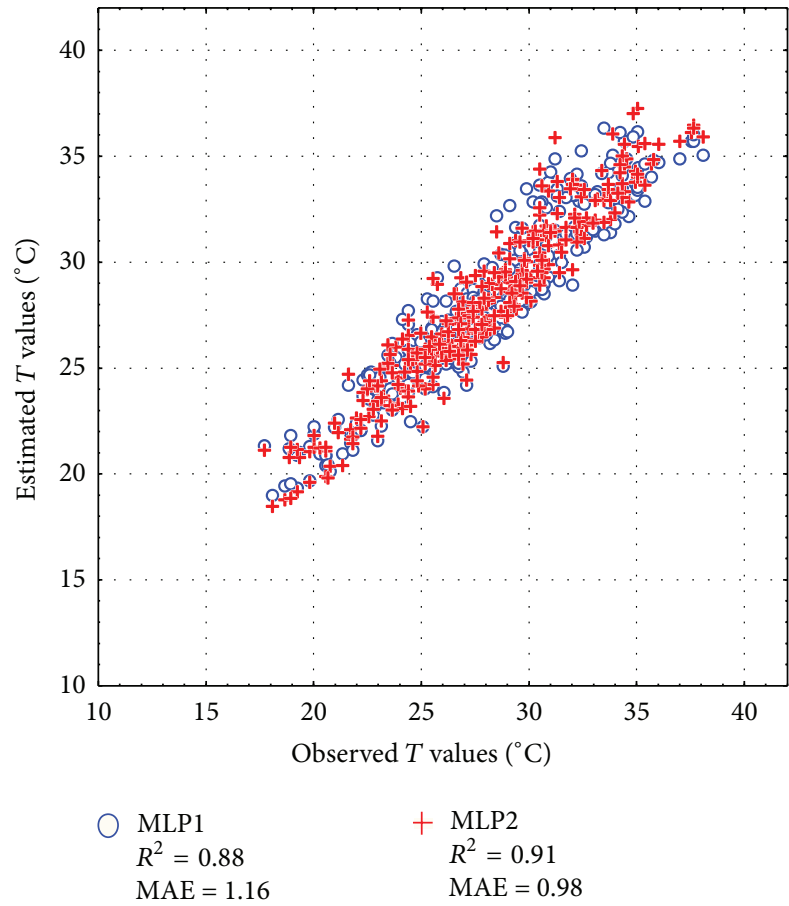

(a)

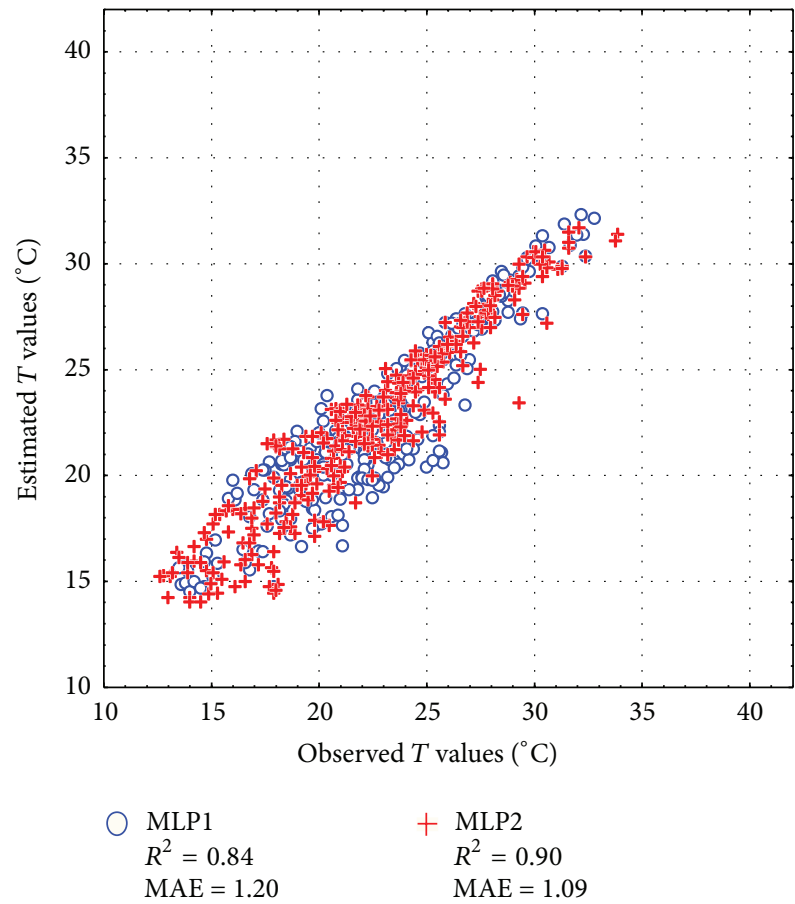

(c)

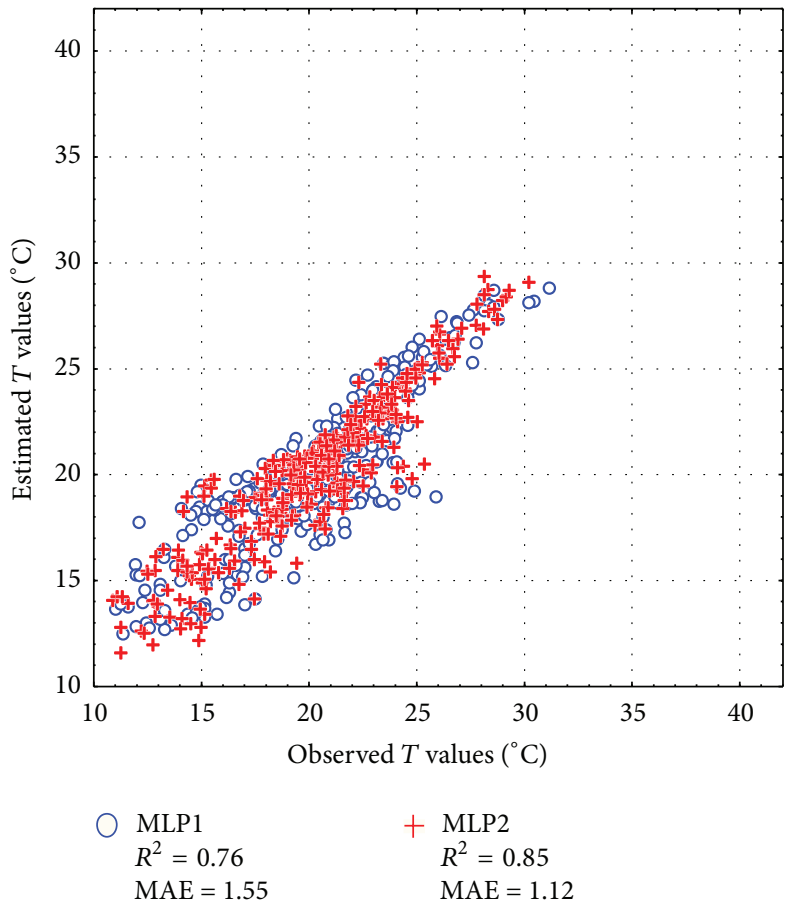

(b)

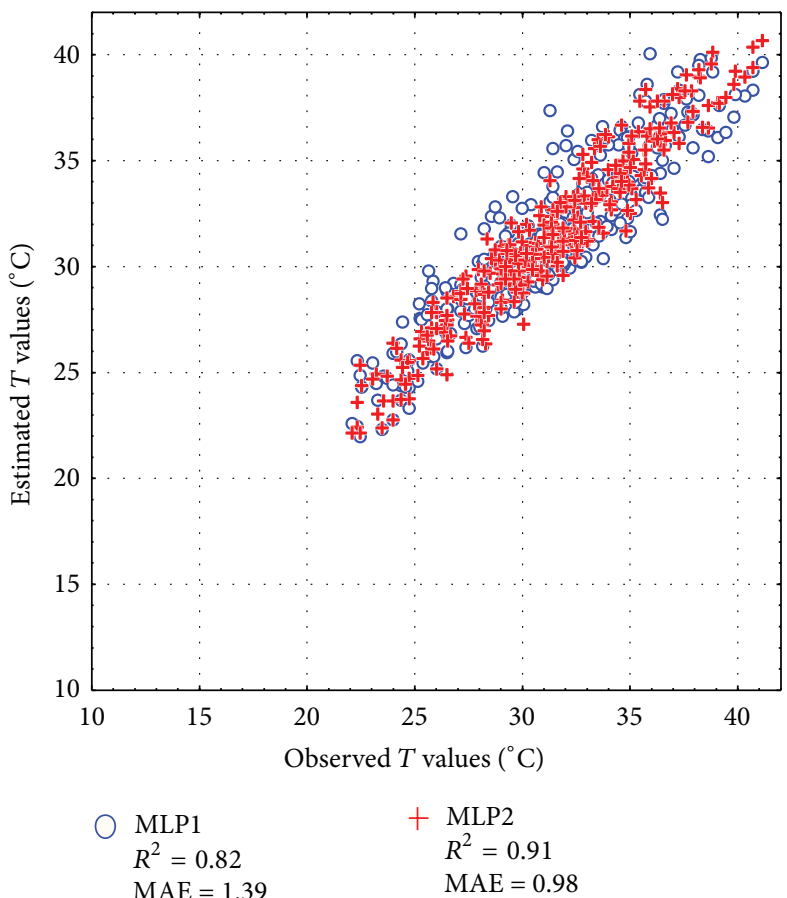

(d)

Figure 3: Scatterplots of observed versus estimated $T$ values in (a) Nea Smirni (S1), (b) top (alt. 1086 m) of Pentelikon Mt. (S2), (c) middle (alt. $796 \mathrm{~m}$ ) of Pentelikon Mt. (S3), and (d) Peristeri (S5) in the GAA, Greece, during summer 2010. T: air temperature, alt.: altitude, Mt.: mountain, GAA: greater Athens area, MLP1: multilayer perceptron model with $T$ as input parameter, MLP2: multilayer perceptron model with $T$ and time of the corresponding $T$ as input parameters, $R^{2}=$ coefficient of determination, $\mathrm{MAE}=$ mean absolute error, and $P<0.05$. 
compared to Nea Smirni (S1) in both applied models (MLP1 and MLP2). In Peristeri, the use of MLP1 showed less accurate $T$ estimations ( $R^{2}$ and MAE values higher and lower, resp.) compared to Nea Smirni and middle alt. of Pentelikon Mt. (S3). In the case of the higher examined alt. of Pentelikon Mt. (Figure 3(b)), $R^{2}$ and MAE took the lowest and highest values, respectively, regardless of the applied MLP model. In general, the applied MLP models were more accurate to estimate $T$ data at greater distances from the reference site.

Both MLP1 and MLP2 models presented, in most cases, better $T$ estimations, in terms of higher $R^{2}$ and lower MAE values, in regions located relatively far away (Nea Smirni and Peristeri) from the reference site (S4) in winter compared to summer. Regarding the studied sites of Pentelikon Mt., located in relatively small distances from S4, better $T$ estimations were found clearly in the case of the top (S2), using the MLP2 model, in summer in relation to winter. The comparison of MLP1 and MLP2 for each examined site showed clearly that MLP2 was always better (higher $R^{2}$ and lower MAE values) than MLP1 in estimating $T$ in both seasons (winter and summer). It has been reported that the input of the actual time of measurement in MLP models attributed to more accurate estimations of the thermohygrometric index in mountainous regions, Greece, in summer [6].

\section{Conclusions}

This study estimated $T$ in the regions of Nea Smirni, Penteli, and Peristeri using one of the most commonly used artificial neural network models, MLP [6]. This estimation was based on $T$ data of a reference station in Penteli. Two MLP approaches were followed: the first (MLP1) used $T$ as input parameter and the second (MLP2) used additionally the time of the corresponding $T$, in accordance with other studies $[6,20]$. We showed that the MLP2 model was better (higher $R^{2}$ and lower MAE) than MLP1 in estimating $T$ in both seasons (winter and summer), independently of the examined region. In general, MLP1 and MLP2 models showed better $T$ estimations in regions located at greater distances (Nea Smirni and Peristeri) from the reference site in relation to the nearby mountainous region in Penteli and in most cases, the greater distance $T$ estimations were more accurate in winter than in summer.

\section{References}

[1] M. Santamouris, G. Mihalakakou, N. Papanikolaou, and D. N. Asimakopoulos, "A neural network approach for modeling the heat island phenomenon in urban areas during the summer period," Geophysical Research Letters, vol. 26, no. 3, pp. 337-340, 1999.

[2] P. Cohen, O. Potchter, and A. Matzarakis, "Daily and seasonal climatic conditions of green urban open spaces in the Mediterranean climate and their impact on human comfort," Building and Environment, vol. 51, pp. 285-295, 2012.

[3] H. E. Landsberg, The Urban Climate, Academic Press, New York, NY, USA, 1981.

[4] L. Cui and J. Shi, "Urbanization and its environmental effects in Shanghai, China," Urban Climate, vol. 2, pp. 1-15, 2012.
[5] R. J. Barry and R. J. Chorley, Atmosphere, Weather and Climate, Routledge, Taylor \& Francis Group, London, UK, 2001.

[6] K. Chronopoulos, A. Kamoutsis, A. Matsoukis, and E. Manoli, "An artificial neural network model application for the estimation of thermal comfort conditions in mountainous regions, Greece," Atmosfera, vol. 25, no. 2, pp. 171-181, 2012.

[7] C. D. Whiteman, Mountain Meteorology, Oxford University Press, New York, NY, USA, 2000.

[8] A. D. Richardson, X. Lee, and A. J. Friedland, "Microclimatology of treeline spruce-fir forests in mountains of the northeastern United States," Agricultural and Forest Meteorology, vol. 125, no. 1-2, pp. 53-66, 2004.

[9] A. Matsoukis, A. Kamoutsis, and A. Chronopoulou-Sereli, "Air temperature and thermal comfort conditions in mountainous and urban regions," International Journal of Sustainable Development and Planning, vol. 4, no. 4, pp. 357-363, 2009.

[10] S. K. Nepal and R. Chipeniuk, "Mountain tourism: toward a conceptual framework," Tourism Geographies, vol. 7, no. 3, pp. 313-333, 2005.

[11] M. Horbert, A. Kirchgeorg, A. Chronopoulou-Sereli, and J. Chronopoulos, Impact of Green on the Urban Atmosphere in Athens, Scientific Series of the International Bureau, Kernforschungsanlage Jülich GmbH, Berlin, Germany, 1988.

[12] M. Guler, B. Cemek, and H. Gunal, "Assessment of some spatial climatic layers through GIS and statistical analysis techniques in Samsum Turkey," Meteorological Applications, vol. 14, no. 2, pp. 163-169, 2007.

[13] D. Jolly, T. Brossard, H. Cardot, J. Cavailhes, M. Hilal, and P. Wavresky, "Temperature interpolation based on local information: the example of France," International Journal of Climatology, vol. 31, no. 14, pp. 2141-2153, 2011.

[14] D. B. Shank, G. Hoogenboom, and R. W. McClendon, "Dewpoint temperature prediction using artificial neural networks," Journal of Applied Meteorology and Climatology, vol. 47, no. 6, pp. 1757-1769, 2008.

[15] K. I. Chronopoulos, I. X. Tsiros, I. F. Dimopoulos, and N. Alvertos, "An application of artificial neural network models to estimate air temperature data in areas with sparse network of meteorological stations," Journal of Environmental Science and Health A, vol. 43, no. 14, pp. 1752-1757, 2008.

[16] O. Kisi and J. Shiri, "Prediction of long-term air temperature using geographical inputs," International Journal of Climatology, 2013.

[17] P. A. Vouterakos, K. P. Moustris, A. Bartzokas, I. C. Ziomas, P. T. Nastos, and A. G. Paliatsos, "Forecasting the discomfort levels within the greater Athens area, Greece using artificial neural networks and multiple criteria analysis," Theoretical and Applied Climatology, vol. 110, no. 3, pp. 329-343, 2012.

[18] B. Smith, G. Hoogenboom, and R. W. McClendon, "Artificial neural networks for automated year-round temperature prediction," Computers and Electronics in Agriculture, vol. 68, no. 1, pp. 52-61, 2009.

[19] A. Kamoutsis, A. Matsoukis, K. Chronopoulos, and E. Manoli, "A comparative study of human thermal comfort conditions in two mountainous regions in Greece during summer," Global Nest Journal, vol. 12, no. 4, pp. 401-408, 2010.

[20] K. Chronopoulos, A. Kamoutsis, and A. Matsoukis, "Thermal comfort estimation in relation to different orientation in mountainous regions in Greece by using artificial neural networks," Global Nest Journal, vol. 14, no. 4, pp. 532-539, 2012. 
[21] Institute of Environmental Research and Sustainable Development (IERSD), "National Observatory of Athens," Climatological means, 2013, http://www.meteo.noa.gr/ENG/iersd_climattable.htm.

[22] A. Flocas, Lessons in Meteorology and Climatology, Zitis Publications, Thessaloniki, Greece, 2nd edition, 1997.

[23] D. E. Rumelhart, G. E. Hinton, and R. J. Williams, "Learning representations by back-propagating errors," Nature, vol. 323, no. 6088, pp. 533-536, 1986.

[24] S. E. Fahlman, "Faster-learning variations on back-propagation: an empirical study," in Proceedings of the 1988 Connectionist Models Summer School, pp. 38-51, Morgan Kaufmann Publishers, San Mateo, Calif, USA, 1988.

[25] L. Fausett, Fundamentals of Neural Networks, Prentice Hall, New York, NY, USA, 1994. 

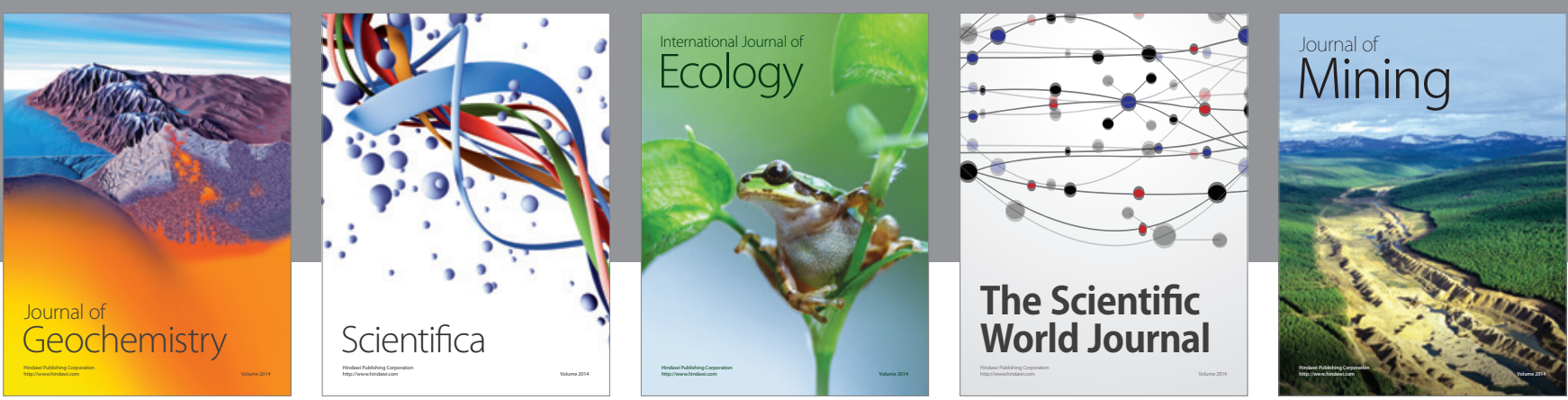

The Scientific World Journal
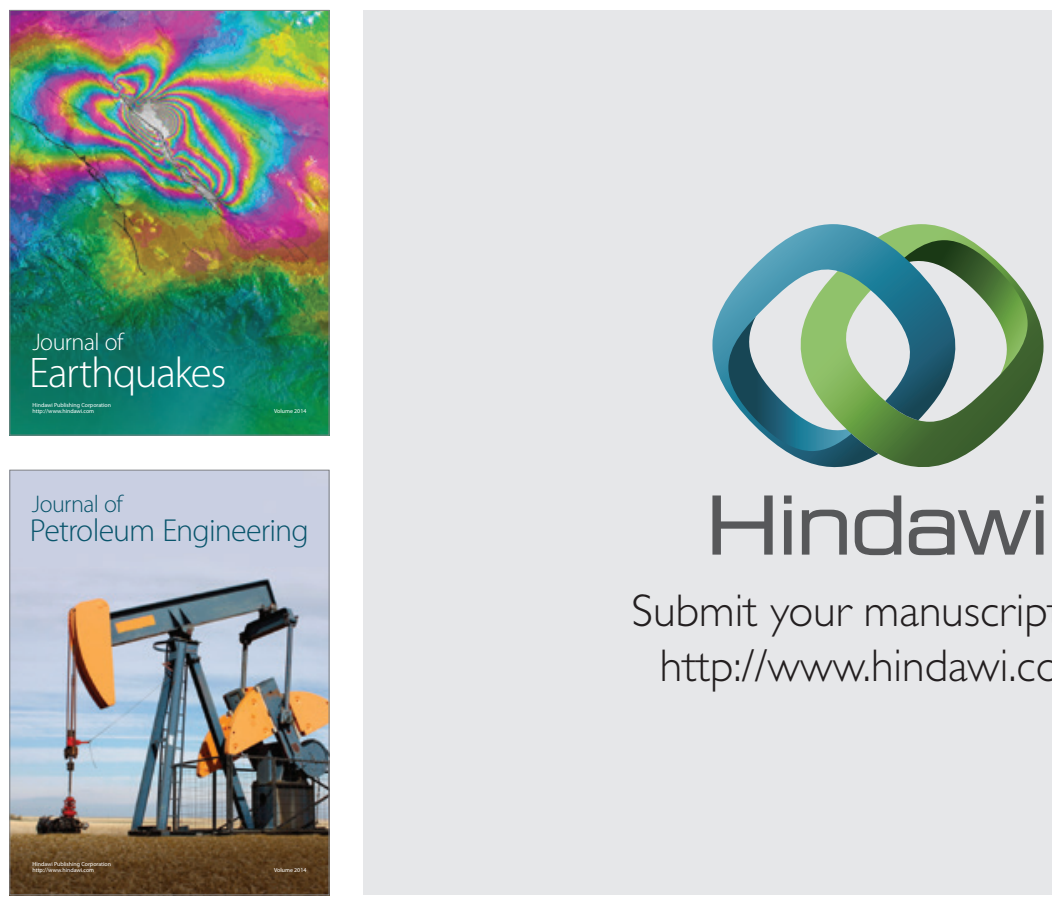

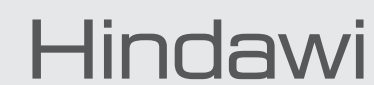

Submit your manuscripts at

http://www.hindawi.com
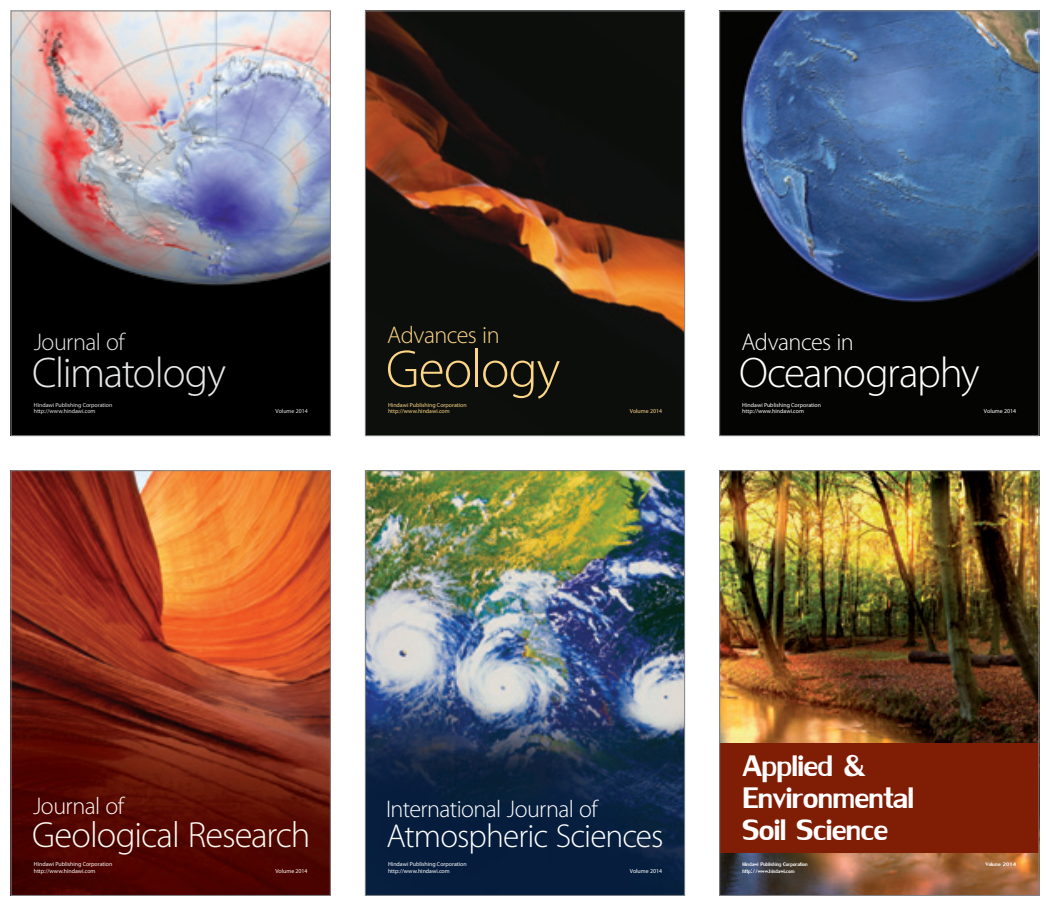
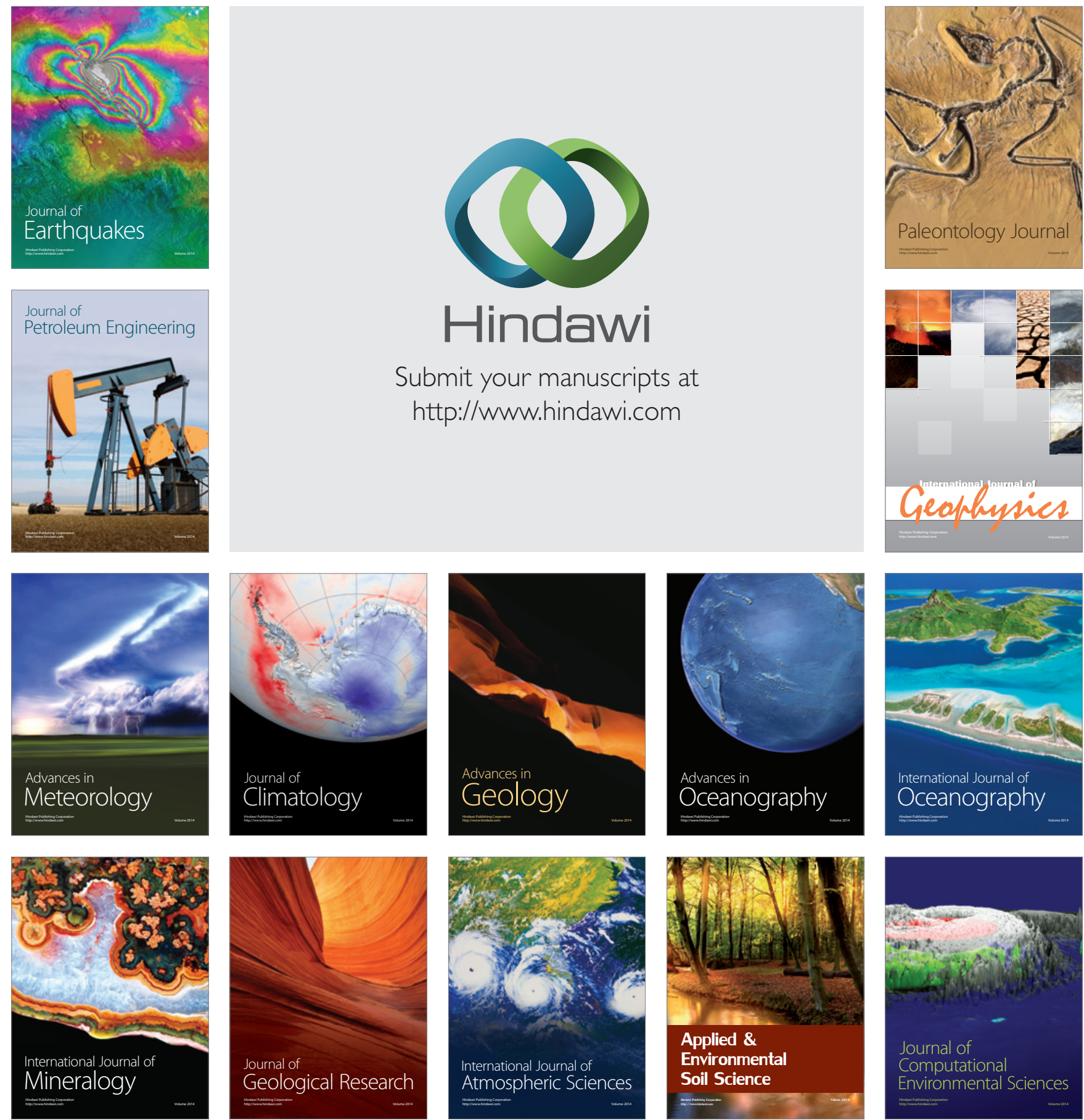